\title{
PERFORMA MESIN MOTOR BERBAHAN BAKAR ETANOL DENGAN PERUBAHAN KAPASITAS MESIN DAN 2 BUSI
}

\author{
Farid Majedi, Fredy Susanto \\ Jurusan Teknik, Politeknik Negeri Madiun, Jalan Serayu 84, Madiun, 63133 \\ e-mail :farid@pnm.ac.id
}

\begin{abstract}
Petroleum reserves are running low. To solve this problem by optimizing the use of petroleum products, used ethanol for gasoline replacement. The motor is modified so that the use of ethanol as a substitute for gasoline can be done. This study aims to see the engine performance with changes in engine capacity and the use of 2 spark plugs. This research method is to modify engine capacity from 113,7 cc to 100,45 cc and use 2 spark plugs. Performance testing of 95\% ethanol fuel modification engine with Dynometer test machine, to determine power, torque and fuel consumption. Performance modification of gasoline engine and 1 spark plug is also tested, then compared. The results showed that the power in the engine capacity of 100.45 cc with ethanol fuel $95 \%$ smaller $7.3 \%$ compared to the power on the engine capacity of $100.45 \mathrm{cc}$ with fuel pertalite. Torque on the engine capacity of 100.45 cc with ethanol fuel $95 \%$ smaller $7.5 \%$ compared to torque on the engine capacity of 100.45 cc with fuel pertalite. Fuel consumption on 100.45 cc engine fueled ethanol 95\% larger 43.6\% compared to fuel consumption in the engine capacity of $100.45 \mathrm{cc}$ with fuel pertalite.
\end{abstract}

Keywords : Engine capacity, 2 spark plugs, ethanol, Power, torque.

\begin{abstract}
ABSTRAK
Cadangan minyak bumi mulai menipis. Untuk mengatasi masalah ini dengan mengoptimalkan penggunaan produk minyak bumi, digunakan etanol untuk pengganti bensin. Motor dimodifikasi agar penggunaan etanol sebagai pengganti bensin dapat dilakukan. Penelitian ini bertujuan untuk melihat performa mesin dengan perubahan kapasitas mesin dan penggunaan 2 busi. Metode penelitian ini adalah memodifikasi kapasitas mesin dari 113,7 cc menjadi 100,45 cc dan menggunakan 2 busi. Pengujian kinerja mesin modifikasi bahan bakar etanol 95\% dengan mesin uji Dynometer, untuk menentukan daya, torsi dan konsumsi bahan bakar. Performa modifikasi mesin bahan bakar bensin dan 1 busi juga diuji, kemudian dibandingkan. Hasil penelitian menunjukkan Daya pada mesin berkapasitas 100,45 cc dengan bahan bakar etanol 95\% lebih kecil 7,3\% dibandingkan pada daya pada mesin berkapasitas 100,45 cC dengan bahan bakar pertalite. Torsi pada mesin berkapasitas 100,45 cc dengan bahan bakar etanol 95\% lebih kecil 7,5\% dibandingkan torsi pada mesin berkapasitas 100,45 cc dengan bahan bakar pertalite. Konsumsi bahan bakar pada mesin berkapasitas 100,45 cc berbahan bakar etanol 95\% lebih besar 43,6\% dibandingkan konsumsi bahan bakar pada mesin berkapasitas 100,45 cc dengan bahan bakar pertalite.
\end{abstract}

Katakunsi : Kapasitas mesin, 2 busi, etanol, Daya, torsi.

\section{PENDAHULUAN}

Cadangan minyak bumi mulai menipis. Untuk mengatasi masalah ini dengan mengoptimalkan penggunaan produk minyak bumi, digunakan etanol untuk pengganti atau campuran bensin pada kendaraan bermotor ${ }^{[8]}$. Substitusi bahan bakar yang bisa digunakan adalah etanol. Etanol sendiri bisa diproduksi dari bahan yang dapat diperbaharui seperti tumbuh-tumbuhan. massa jenis Etanol berbeda dengan bahan bakar fosil dan mesin yang menggunakan campuran etanol akan sulit dinyalakan pada saat awal pengoperasian dll [2]. Nilai Lower Heating Value (LHV) etanol lebih rendah jika dibandingkan dengan bensin. Sehingga Torsi akan lebih kecil dibanding bensin dengan kondisi mesin standart [5]. Untuk 
meningkatkan performa dapat dengan cara meningkatkan kapasitas silinder mesin ${ }^{[4]}$.

Dari penelitian sebelumnya antara lain : Dengan variasi Ignition Timing Mapping $\left(10^{\circ}, 13^{\circ}, 16^{\circ}, 19^{\circ}\right.$, dan $21^{\circ}$ BTDC) menggunakan Eddy Current Dynamometer nilai AFR Pertalite yang cenderung berada di atas Premium yang sesuai dengancanalisa kalor laten penguapan, serta mapping ignition timingdengan kenaikan rata - rata torsi, daya, dan bmep sebesar $6.393 \%$ relatif terhadap pengapian standar, efisiensi thermal mengalami kenaikan sebesar $5.409 \%$, sfc mengalami penurunan ratarata sebesar $1.97 \%$, serta emisi CO dan HC mengalami penurunan, masing masing sebesar $5.405 \%$ dan $7.443 \%{ }^{[3]}$. Dengan menggunakan busi 2 lebih efisien dibandingkan dengan busi 1 untuk pembakaran ethanol 94-100\%. Data hasil pengujian di analisa dan di bandingkan dengan konsentrasi pada emisi gas buang, konsumsi bahan bakar, torsi dan daya. ${ }^{[7]}$, dengan pencampuran bensin dan etanol $(0 \%, 5 \%, 15 \%, 25 \%$ etanol) menghasilkan penurunan nilai kalor pada campuran etanol 5\%, 15\%, $25 \%$, dan daya tertinggi ada pada campuran $15 \%$ yaitu 9,02 kW. [1], Dengan simulasi variasi bentuk permukaan torak cekung dan cembung memberi hasil torak cembung menghasilkan tingkat kompresi lebih tinggi dan meningkatkan daya motor yang besar ${ }^{[9]}$.

Dengan permasalahan ini penulis melakukan penelitian dengan modifikasi kapasitas mesin dan 2 busi untuk meningkatkan performasi mesin menggunakan bahan bakar etanol 95\%. Pengujian dilakukan untuk dengan menguji performa mesin mofidikasi dengan dinamometer jenis chassis, yaitu untuk mendapatkan milai daya, torsi pada kapasitas silinder 113.7 cc, 100,45 cc dengan satu busi (standar) berbahan bakar pertalite dibandingkan dengan mesin modifikasi kapasitas silinder
100.45 cc dengan dua busi berbahan bakar etanol 95\%.

Penelitian ini bertujuan untuk meningkatkan performa mesin bahan bakar etanol 95\% dengan cara modifikasi kapasitas mesin dan 2 busi. Hasil yang diharapkan memperoleh performa mesin meningkat (torsi dan Daya).

\section{METODE PENELITIAN}

Dalam penelitian ini dilakukan modifikasi kapasistas mesin dari 113,7 cc menjadi 110,45 cc ( Gambar 1) dan 2 busi (Gambar 2).

Penelitian ini merupakan penelitian eksperimen (experimental research) yang bertujuan untuk menyelidiki kemungkinan pengaruh variabel Independen (kapasitas mesin dan 2 busi) terhadap variasi dependen (Daya, torsi dan konsumsi bahan bakar) dalam kelompok eksperimental.

Pada pengujian ini dilakukan untuk menguji performa mesin mofidikasi dengan dinamometer jenis chassis, yaitu untuk mendapatkan milai daya, torsi pada kapasitas silinder 113.7 cc (1busi), 100,45 cc (2 busi) berbahan bakar pertalite dibandingkan dengan mesin modifikasi kapasitas silinder 100.45 сc dengan dua busi berbahan bakar etanol 95\%.

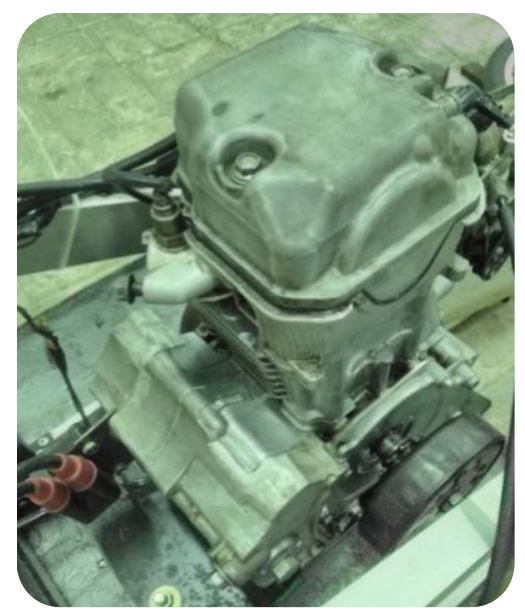

Gambar 1. Mesin Modifikasi untuk bahan bakar ethanol 


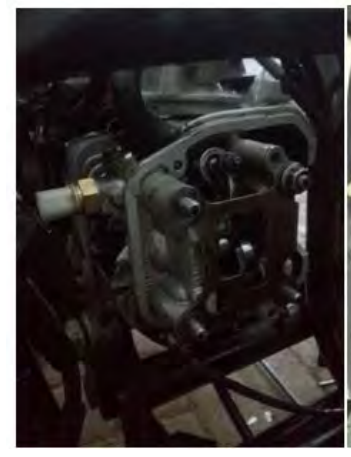

a)

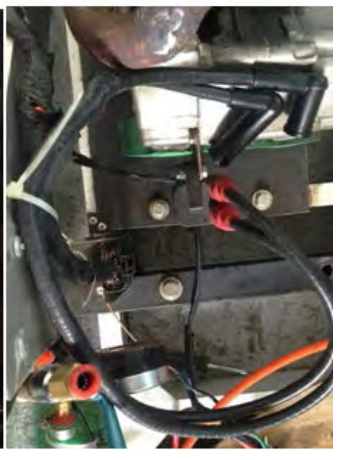

b)
Gambar 2. a) Pemasangan kepala silinder 2 busi b) Pemasangan koil T120SS

\section{HASIL dan PEMBAHASAN}

\section{Hasil Pengujian performa mesin (Daya dan torsi)}

Setelah hasil modifikasi mesin selesai pengujian performa mesin mofidikasi dengan dinamometer jenis chassis, yaitu untuk mendapatkan milai daya, torsi pada kapasitas silinder 113.7 cc, 100,45 cc dengan satu busi (standar) berbahan bakar pertalite dibandingkan dengan mesin modifikasi kapasitas silinder 100.45 cc dengan dua busi berbahan bakar etanol 95\%. Dari beberapa pengujian diperoleh rangkuman data hasil pengujian pada tabel 1 dan tabel 2.

\section{Hasil Pengujian Konsumsi Bahan Bakar}

Pengujian konsumsi bahan bakar per 30 detik pada 3000, 4000, 5000 dan 6000 rpm. Dari data konsumsi bahan bakar cc/dt dimasukkan dalam rumus laju konsumsi bahan bakar.

\section{Analisa Pengaruh Putaran Mesin terhadap Daya pada Mesin}

Gambar 3 menunjukkan daya pada mesin kapasitas silinder 113,7 cc dengan bahan bakar pertalite mempunyai daya tertinggi 8,1 HP pada 4000 rpm dan daya terendah 5,4 HP pada 2500 rpm. Daya pada mesin kapasitas silinder 100,45 cc dengan bahan bakar pertalite, daya tertinggi diperoleh pada 7500 rpm dengan nilai daya 6,3 HP dan terendah 3,5 HP pada
9500 rpm. Sedang daya pada mesin kapasitas silinder 100,45 cc dengan bahan bakar etanol 95\% tertinggi diperoleh pada 7000 rpm dengan nilai daya 6,7 HP dan terendah 3,4 HP pada $2500 \mathrm{rpm}$.

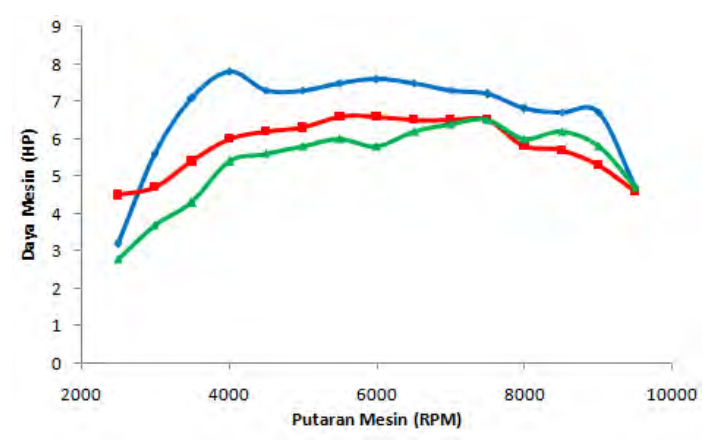

Gambar 3. Grafik hubungan daya dan putaran mesin

Sumber : Data Primer yang diolah, 2018

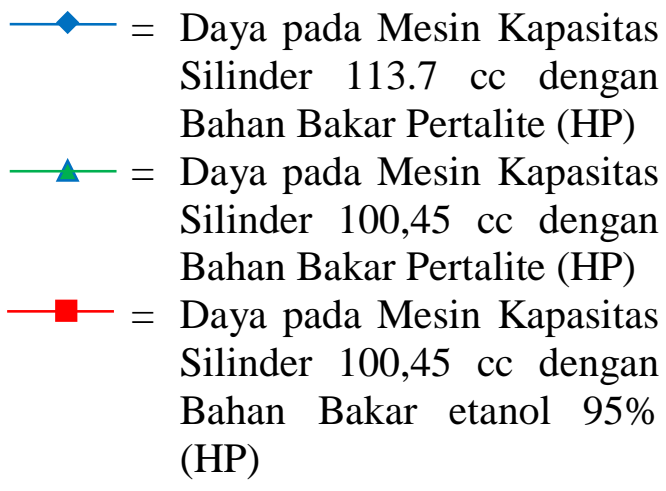

Dari Gambar 3 tersebut telihat Daya mesin dengan kapasitas silinder 113.7 cc dengan bahan bakar pertalite lebih besar dibanding dengan mesin kapasitas silinder 100,45 cc dengan bahan bakar pertalite dan mesin kapasitas silinder 100,45 cc dengan bahan bakar etanol 95\%. Hal ini dikarenakan dengan dengan kapasitas mesin besar maka torak dan ruang bakar juga lebih besar sehingga tenaga dan data yang dihasilkan mesin menjadi besar. Daya mesin kapasitas silinder 100,45 сc dengan bahan bakar etanol 95\% sedikit lebih kecil dari mesin kapasitas silinder 100,45 cc dengan bahan bakar pertalite. Hal ini dikarenakan bahan bakar etanol 95\% mempunyai massa jenis lebih tinggi dari pada pertalite sehingga membutuhkan lebih banyak volume 
etanol daripada pertalite pada rpm yang sama. Sesuai dengan penelitian Pada penelitian, Mega Nur Sasongko (2016), mengatakan daya efektif cenderung menurun dengan meningkatnya jumlah volumetrik etanol dalam campuran bahan bakar untuk semua variasi putaran mesin. Daya mesin kapasitas silinder 100,45 cc dengan bahan bakar etanol 95\% menurun 7,3 \% dibanding mesin kapasitas silinder 100,45 cс dengan bahan bakar pertalite.

\section{Analisa Pengaruh Putaran Mesin terhadap Torsi roda}

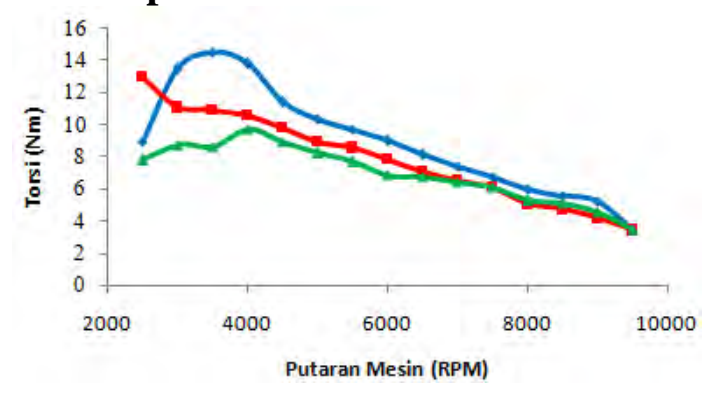

Gambar 4. Grafik hubungan torsi roda dan putaran mesin

Sumber : Data Primer yang diolah, 2018

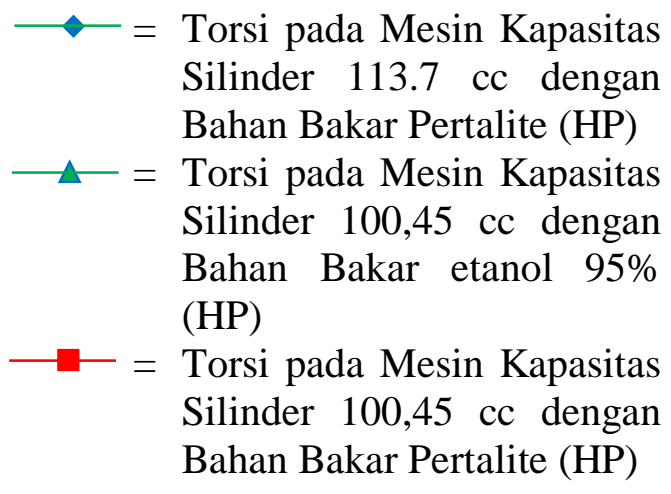

Gambar 4 menunjukkan torsi pada putaran rendah kecil dan terus naik mencapai maksimum pada putaran 2500 rpm - 3500 rpm, dan kemudian terus menurun pada putaran yang lebih tinggi. Pada putaran tinggi, Torsi mengalami penurunan karena pengaruh volume campuran udara bahan bakar yang cenderung berkurang dengan naiknya putaran. Volume campuran udara bahan bakar karena pada putaran tinggi derajat pengisian silinder yang tidak sempurna. Karena waktu yang sangat singkat Katup hisap dan buang cenderung mengalami floating yaitu tidak dapat menutup secara sempurna yang diakibatkan. Penurunan torsi ini juga diakibatkan oleh kenaikan torsi gesek (torsi untuk mengatasi hambatan gesek di dalam mesin) yang bertambah besar seiring meningkatnya kecepatan piston bergerak naik - turun.

Torsi pada mesin kapasitas silinder 113.7 cc dengan bahan bakar pertalite mempunyai Torsi tertinggi $15,48 \mathrm{Nm}$ pada $3500 \mathrm{rpm}$ dan torsi terendah 3,45 pada 9500 RPM. Torsi pada mesin kapasitas silinder 100,45 cc dengan bahan bakar pertalite torsi tertinggi diperoleh pada $2500 \mathrm{rpm}$ dengan nilai torsi $11,17 \mathrm{Nm}$ dan terendah 4,0 $\mathrm{Nm}$ pada $9500 \mathrm{rpm}$. Sedang torsi pada mesin kapasitas silinder 100,45 cc dengan bahan bakar etanol 95\% tertinggi diperoleh pada $3000 \mathrm{rpm}$ dengan nilai daya 10,04 $\mathrm{Nm}$ dan terendah 3,75 Nm pada $9500 \mathrm{rpm}$.

Dari Gambar 4 menunjukkan torsi mesin kapasitas silinder $113.7 \quad$ cc dengan bahan bakar pertalite mempunyai nilai yang lebih besar dibanding dengan mesin kapasitas silinder 100,45 cc dengan bahan bakar pertalite dan mesin kapasitas silinder 100,45 cc dengan bahan bakar etanol 95\%. Torsi mesin kapasitas silinder 100,45 cc dengan bahan bakar etanol 95\% lebih kecil 7,5 \% dibanding mesin kapasitas silinder 100,45 cc dengan bahan bakar pertalite, hal ini disebabkan karena nilai kalor (heating value) etanol yang lebih rendah dari pertalite sehingga temperatur silinder menjadi menurun dan mengakibatkan misfire dan akhirnya menurunkan Torsi[6].

\section{Analisa Pengaruh Putaran Mesin terhadap Laju Konsumsi Bahan Bakar}

Pada Gambar 5 terlihat Pada pengujian konsumsi bahan bakar, mesin yang memiliki kapasitas silinder lebih besar (113.7 cc) membutuhkan lebih banyak bahan bakar dibanding mesin 100.45 cc 
selama proses pengujian dengan bahan bakar yang sama. Hal ini dikarenakan kapasitas silinder yang lebih besar akan membutuhkan asupan udara (oksigen) dan bahan bakar yang lebih besar dibanding dengan kapasitas silinder yang lebih kecil. Laju Konsumsi mesin dengan kapasitas 113,7 cc lebih besar $11,3 \%$ dibanding dengan Laju Konsumsi mesin dengan kapasitas 100,45 cc dengan bahan bakar yang sama pertalite.

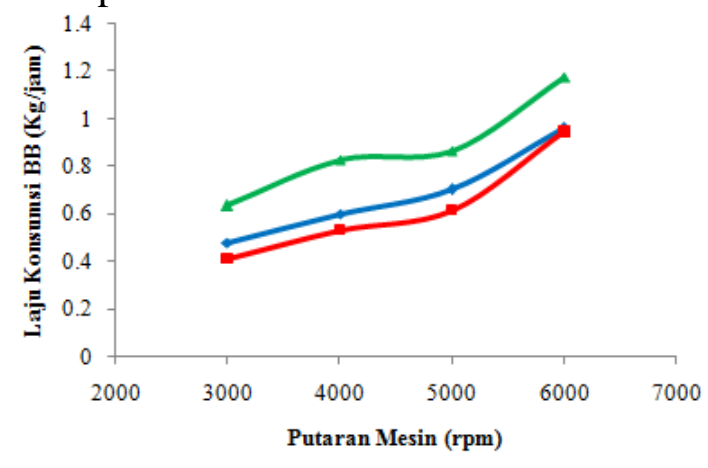

Gambar 5. Grafik hubungan laju konsumsi bahan bakar dan putaran mesin

Sumber : Data Primer yang diolah, 2018

$\begin{aligned} \longrightarrow & =\text { Konsumsi Bahan Bakar } \\ & \text { pada Mesin Kapasitas Silinder } \\ & 113.7 \text { cc dengan Bahan Bakar } \\ & \text { Pertalite (HP) } \\ & =\text { Konsumsi Bahan Bakar } \\ & \text { pada Mesin Kapasitas Silinder } \\ & \text { 100,45 cc dengan Bahan Bakar } \\ & \text { etanol 95\% (HP) } \\ & =\text { Konsumsi Bahan Bakar } \\ & \text { pada Mesin Kapasitas Silinder } \\ & \text { 100,45 cc dengan Bahan Bakar } \\ & \text { Pertalite (HP) }\end{aligned}$

Sedangkan penggunaan bahan bakar etanol menghasilkan laju konsumsi bahan bakar yang lebih banyak dibanding bensin. Hal ini ditunjukkan dalam Gambar 5. Menurut Mega Nur Sasongko (2016), dengan perbedaan nilai kalor antara bensin dan etanol maka kecenderungan terjadi peningkatan konsumsi bahan bakar. Etanol yang memiliki nilai kalor lebih rendah daripada bensin akan memerlukan lebih banyak bahan bakar agar menghasilkan daya mesin yang sama.

\section{KESIMPULAN}

Efek Modifikasi kapasitas mesin yang diperkecil dan penggunaan dua busi berpengaruh terhadap performa mesin, dengan kapasitas mesin sama $(100,45$ cc) tapi bahan bakar pertalite (satu busi) dengan etanol (dua busi) maka performa mesin dengan bahan bakar etanol lebih kecil dibanding mesin motor dengan bahan bakar pertalite. Nilai daya dan torsi mesin motor bahan bakar etanol lebih kecil dari dibanding nilai daya dan torsi mesin motor bahan bakar pertalite Untuk penelitian lebih lanjut perlu diteliti bagaimana performa mesin dapat sama antara bahan bakar etanol dengan bahan bakar pertalite dengan kapasitas mesin sama.

\section{DAFTAR PUSTAKA}

[1] Agrariksa, F. A., Susilo, B., Nugroho, W. A., Uji Performansi Motor bakar Bensin (On Chassis) Menggunakan Campuran Premium dan Etanol. Jurnal Keteknikan Pertanian Tropis dan Biosistem, 1 (3), 194-203.

[2] Aji, A., Triyono, J., Triyono, T., Aji, A., Triyono, J., Triyono, T., 2017. Studi Eksperimental Pengaturan Waktu Pengapian Pada Mesin 4 Langkah 1 Silinder Berbahan Bakar E25. Jurnal Rotasi 19 (3), 165-171.

[3] Gurnito, A., Sudarmanta, B., 2016. Pengaruh Ignition Timing Mapping Terhadap Unjuk Kerja dan Emisi Engine SINJAI 650 CC Berbahan Bakar Pertalite RON 90. Jurnal Teknik ITS. 5 (1), B30-35.

[4] Majedi, F., \& Puspitasari, I., 2017. Optimasi Daya Dan Torsi Pada Motor 4 Tak Dengan Modifikasi Crankshaft Dan Porting Pada 
Cylinder Head. Jurnal Teknologi

Terpadu. 5 (1), 82-89.

[5] Rahmad, H., Sasongko, M. N., Widjayanti, W., 2016. Pengaruh Prosentase Etanol Terhadap Torsi Dan Emisi Motor Indirect Injection Dengan Memodifikasi Engine Controle Module. Jurnal Rekayasa Mesin 7 (2), 49 - 54.

[6] Sasongko, M., Wijayanti, W., 2016, Pengaruh prosentase etanol terhadap daya dan konsumsi bahan bakar mesin pembakaran busi, Jurnal Energi dan Manufaktur, 9 (2) : 147149.

[7] Setityoadi, W., 2016 Essay In Analisa Kinerja Mesin Motor 4 Langkah Berbahan Bakar Ethanol 94 - 100 \% Dengan Penerapan 2 Busi. (skripsi Universitas Muhammadiyah Malang).

[8] Sugiyanto, Didik. 2014. Pengaruh Variasi Jenis Busi Dan Campuran Bensin Methanol Terhadap Kinerja Motor 4 Tak. Jurnal Sainstech Politeknik Indonusa Surakarta, 1 (2), [8.p.].

[9] Wijayanti, F., \& Irwan, D., 2014. Analisis Pengaruh Bentuk Permukaan Piston Terhadap Kinerja motor Bensin. Jurnal Imiah Teknik Mesin, 2 (1), 34-42 


\section{LAMPIRAN}

Tabel 1.

Hasil pengujian Daya pada Mesin Kapasitas Silinder 113.7 cc dengan Bahan Bakar Pertalite, Mesin Kapasitas Silinder 100,45 Cc Dengan Bahan Bakar Pertalite dan Mesin Kapasitas Silinder 100,45 cc dengan bahan bakar etanol 95\%

\begin{tabular}{|c|c|c|c|c|}
\hline No & $\begin{array}{c}\text { Putaran } \\
\text { Mesin (RPM) }\end{array}$ & $\begin{array}{c}\text { Daya Mesin } \\
\text { Kapasitas 113,7 cc } \\
\text { dengan bahan bakar } \\
\text { pertalite (HP) }\end{array}$ & $\begin{array}{c}\text { Daya Mesin } \\
\text { Kapasitas 100,45 cc } \\
\text { dengan bahan } \\
\text { bakar Pertalite } \\
\text { (HP) }\end{array}$ & $\begin{array}{c}\text { Daya Mesin } \\
\text { Kapasitas 100,45 } \\
\text { cc dengan bahan } \\
\text { bakar etanol 95\% } \\
\text { (HP) }\end{array}$ \\
\hline 1 & 2500 & 3,2 & 4,5 & 2,8 \\
\hline 2 & 3000 & 5,6 & 4,7 & 3,7 \\
\hline 3 & 3500 & 7,1 & 5,4 & 4,3 \\
\hline 4 & 4000 & 7,8 & 6,0 & 5,4 \\
\hline 5 & 4500 & 7,3 & 6,2 & 5,6 \\
\hline 6 & 5000 & 7,3 & 6,3 & 5,8 \\
\hline 7 & 5500 & 7,5 & 6,6 & 6,0 \\
\hline 8 & 6000 & 7,6 & 6,6 & 5,8 \\
\hline 9 & 6500 & 7,5 & 6,5 & 6,2 \\
\hline 10 & 7000 & 7,3 & 6,5 & 6,4 \\
\hline 11 & 7500 & 7,2 & 6,5 & 6,5 \\
\hline 12 & 8000 & 6,8 & 5,8 & 6,0 \\
\hline 13 & 8500 & 6,7 & 5,7 & 6,2 \\
\hline 14 & 9000 & 6,7 & 5,3 & 5,8 \\
\hline 15 & 9500 & 4,7 & 4,6 & 4,7 \\
\hline
\end{tabular}

Sumber : Data Sekunder yang diolah, Tahun 2018 
Tabel 2.

Hasil pengujian Torsi pada Mesin Kapasitas Silinder 113.7 cc dengan Bahan Bakar Pertalite, Mesin Kapasitas Silinder 100,45 Cc Dengan Bahan Bakar Pertalite dan mesin kapasitas silinder 100,45 cc dengan bahan bakar etanol 95\%

\begin{tabular}{lcccc}
\hline No & $\begin{array}{c}\text { Putaran } \\
\text { Mesin (RPM) }\end{array}$ & $\begin{array}{c}\text { Torsi Mesin } \\
\text { Kapasitas 113,7 } \\
\text { cc dengan } \\
\text { bahan bakar } \\
\text { pertalite (Nm) }\end{array}$ & $\begin{array}{c}\text { Torsi Mesin } \\
\text { Kapasitas 100,45 cc } \\
\text { dengan bahan bakar } \\
\text { Pertalite (Nm) }\end{array}$ & $\begin{array}{c}\text { Torsi Mesin Kapasitas } \\
\text { 100,45 cc dengan bahan } \\
\text { bakar etanol 95\% (Nm) }\end{array}$ \\
\hline 1 & 2500 & 8,94 & $\mathbf{1 2 , 9 8}$ & 7,82 \\
2 & 3000 & 13,49 & 11,09 & 8,75 \\
3 & 3500 & $\mathbf{1 4 , 5 1}$ & 10,92 & 8,62 \\
4 & 4000 & 13,81 & 10,61 & $\mathbf{9 , 7 0}$ \\
5 & 4500 & 11,42 & 9,85 & 8,92 \\
6 & 5000 & 10,34 & 8,95 & 8,24 \\
7 & 5500 & 9,69 & 8,57 & 7,71 \\
8 & 6000 & 9,00 & 7,84 & 6,85 \\
9 & 6500 & 8,15 & 7,07 & 6,78 \\
10 & 7000 & 7,45 & 6,55 & 6,45 \\
11 & 7500 & 6,74 & 6,09 & 6,15 \\
12 & 8000 & 6,03 & 5,09 & 5,31 \\
13 & 8500 & 5,59 & 4,75 & 5,11 \\
14 & 9000 & 5,27 & 4,19 & 4,58 \\
15 & 9500 & 3,51 & 3,45 & 38 \\
\hline
\end{tabular}

Sumber : Data Sekunder yang diolah, Tahun 2018

Tabel 3.

Perbandingan Laju Konsumsi Bahan Bakar pada Mesin Kapasitas Silinder 113.7 cc (Pertalite), 100.45 cc (Pertalite) dan 100.45 cc (Etanol 95\%)

\begin{tabular}{ccccc}
\hline No & $\begin{array}{c}\text { Putaran Mesin } \\
\text { (RPM) }\end{array}$ & $\begin{array}{c}\text { Laju Konsumsi BB } \\
\text { Mesin 113.7 cc } \\
\text { (Pertalite) } \\
\text { (kg/jam) }\end{array}$ & $\begin{array}{c}\text { Laju Konsumsi } \\
\text { BB Mesin 100.45 } \\
\text { cc (Pertalite) } \\
\text { (kg/jam) }\end{array}$ & $\begin{array}{c}\text { Laju Konsumsi } \\
\text { BB Mesin 100.45 } \\
\text { cc (Etanol 95\%) } \\
\text { (kg/jam) }\end{array}$ \\
\hline 1 & 3000 & 0,48 & 0,41 & 0,64 \\
2 & 4000 & 0,60 & 0,53196 & 0,83 \\
3 & 5000 & 0,70 & 0,62 & 0,87 \\
4 & 6000 & 0,966 & 0,94 & 1,17 \\
\hline
\end{tabular}

Sumber : Data Sekunder yang diolah, Tahun 2018 